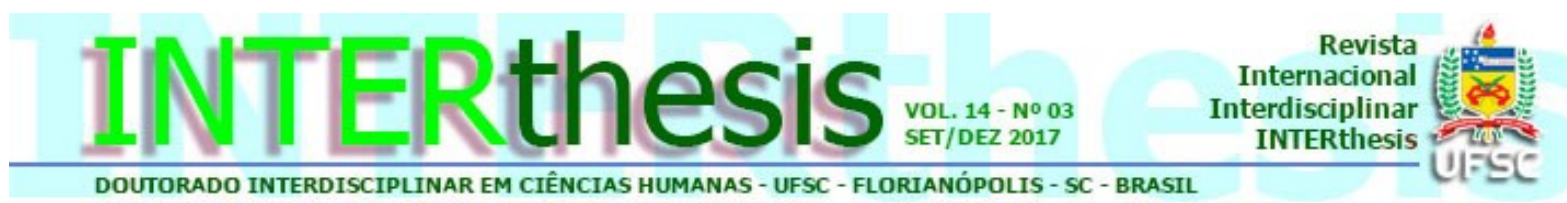

\title{
O PRINCÍPIO DA SUBSIDIARIEDADE E O FORTALECIMENTO DA CIDADANIA NO ESPAÇO LOCAL COMO INSTRUMENTO DE EFETIVAÇÃO DE POLÍTICAS PÚBLICAS DE PROTEÇÃO AMBIENTAL
}

\section{Resumo:}

Tatiele Gisch Kuntz ${ }^{1}$

O cuidado com o meio ambiente possui papel fundamental na preservação da qualidade de vida, pois os problemas ambientais decorrentes da expansão urbana, assim como dos altos níveis de consumo e descarte, são fontes de inquietação global e desafiam a sociedade e o poder público. Diante dessa realidade, o presente artigo objetiva verificar se o fortalecimento da cidadania no espaço local, com base no princípio da subsidiariedade, pode se configurar como um instrumento de efetivação de políticas públicas de proteção ambiental. Para isso, optou-se por uma abordagem qualitativa do tema. Concluiu-se, por conseguinte, que a aplicação do princípio da subsidiariedade pode ensejar o fortalecimento da cidadania no espaço local e o desenvolvimento de políticas públicas que tratem da temática ambiental, desde que sejam ampliados, nos municípios, os espaços de participação da sociedade nas decisões políticas.

Palavras-Chave: Cidadania. Subsidiariedade. Poder Local. Políticas Públicas. Proteção Ambiental.

\section{INTRODUÇÃO}

No Brasil, a questão ambiental ganhou relevância no último século, principalmente em virtude do crescimento exagerado e desorganizado dos grandes centros urbanos, os quais causam sérios impactos ambientais.

É nesse contexto que se insere o papel do poder público e da sociedade na tutela ambiental, pois a Constituição, em seu artigo 225, dispõe que é dever do poder público e da coletividade a defesa e a preservação do meio ambiente ecologicamente equilibrado, bem de uso comum e essencial à qualidade de vida.

Nessa seara, o presente artigo objetiva verificar se o fortalecimento da cidadania no espaço local, com base no princípio da subsidiariedade, pode se

\footnotetext{
${ }^{1}$ Mestre em Direitos Sociais e Políticas Públicas pela Universidade de Santa Cruz do Sul, Santa Cruz do Sul, RS. E-mail: tatiele.g.k@gmail.com

2 Mestre em Direito pelo Programa de Pós-Graduação em Direito da Universidade de Santa Cruz do Sul, Santa Cruz do Sul, RS. E-mail: ccwerle@yahoo.com.br
} 
configurar como um instrumento de efetivação de políticas públicas de proteção ambiental.

Diante desse cenário, o estudo se justifica, pois procura demonstrar a importância da aplicação do princípio da subsidiariedade no espaço local como instrumento de fortalecimento da cidadania e desenvolvimento de políticas públicas ambientais. Isso porque, trabalha-se com a hipótese de que a aplicação do princípio da subsidiariedade pode ensejar o fortalecimento da cidadania no espaço local e o desenvolvimento de políticas públicas que tratem dessa temática.

Nessa conjuntura, procura-se responder a seguinte indagação: A aplicação do princípio da subsidiariedade pode ensejar o fortalecimento da cidadania no espaço local e o desenvolvimento de políticas públicas que tratem da temática ambiental?

Para exame do proposto, realizou-se um estudo de cunho qualitativo visando a interpretação e análise dos dados por meio da pesquisa bibliográfica. Utilizou-se, ainda, o método dedutivo, o qual parte de argumentos gerais para particulares.

Assim, a reflexão que segue, no primeiro momento, trata da proteção ambiental e da importância das políticas públicas. Após, passa-se a discorrer a respeito do princípio da subsidiariedade e da cidadania no espaço local. Por fim, aborda-se como o fortalecimento da cidadania nos municípios pode ser um instrumento de efetivação de políticas públicas de proteção ambiental.

\section{A PROTEÇÃO AMBIENTAL E AS POLÍTICAS PÚBLICAS}

A instituição de políticas públicas que visem à proteção ambiental, além de um desafio e um dever atribuído pela Constituição Federal ao poder público nas três esferas de governo, está intimamente ligada à evolução dos direitos fundamentais e no reconhecimento do homem como um ser detentor de direitos (SARLET, 2009).

De acordo com Antunes (2008), foi por meio da Declaração de Estocolmo de 1972 que o meio ambiente foi elevado ao nível de direito fundamental, conforme se verifica da análise do disposto no princípio $\mathrm{n}^{\circ} 1$ da referida declaração:

O homem tem o direito fundamental à liberdade, à igualdade e ao desfrute de condições de vida adequada em um meio cuja qualidade lhe permite levar uma vida 
digna e gozar de bem-estar, tendo a solene obrigação de proteger e melhorar esse meio para as gerações presente e futura. (BRASIL, 1972).

A respeito da questão, Granziera (2009) aduz que foi o aludido princípio que serviu de inspiração ao legislador constituinte para a redação do caput do artigo 225 da Constituição Federal de 1988, haja vista que esse, ao mesmo tempo em que garante o direito ao meio ambiente ecologicamente equilibrado a todos, impõe ao poder público e a coletividade o dever de preservá-lo e mantê-lo sadio para as presentes e futuras gerações.

Dessa forma, resta evidenciado que a proteção ambiental, como direito fundamental, não busca somente proteger ao meio ambiente, mas a vida de uma coletividade, cuja titularidade é imensurável. Daí a importância do desenvolvimento e implementação de políticas públicas, em especial na esfera local, que tenham como finalidade assegurar a efetivação deste direito.

Segundo Schmidt (2008), conceituar políticas públicas remete à esfera pública e aos problemas que essa possui, já que diz respeito ao plano das questões coletivas, da polis. No entanto, convém lembrar que o público difere do particular, do privado, do individual, pois diz respeito a uma dimensão mais ampla da qual, inclusive, se distingue o estatal e o não-estatal.

Para o autor, o estudo da política passa por três dimensões ou três diferentes termos que derivam da língua inglesa, quais sejam: polity ,politics, policy . O primeiro se refere à dimensão institucional da política, o segundo diz respeito à dimensão processual e, o terceiro, por sua vez, ao conteúdo material concreto da política, ou seja, às políticas públicas (SCHMIDT, 2008).

De acordo com Souza Junior (2002, p. 64), o tema das políticas públicas, em que pese ser proveniente da teoria política, tornou-se uma categoria de interesse também para o Direito, especialmente, a partir do momento em que "necessidades sociais nunca antes sentidas passaram a reclamar ações do poder público, muitas de natureza prestacional, atingindo áreas da vida pessoal e social que estavam fora do âmbito da política".

Nesse aspecto, Bucci (2006, p. 241) leciona que "adotar a concepção das políticas públicas em direito consiste em aceitar um grau maior de interpenetração entre as esferas jurídicas e políticas", ou seja, consiste em reconhecer a 
comunicação que há entre as duas esferas, tornando público os processos dessa inter-relação na estrutura burocrática do poder.

Nessa perspectiva, é possível afirmar que as políticas públicas são o meio de ação através do qual o Estado, em resposta as diversas demandas sociais, procura concretizar direitos e garantias fundamentais, sempre em prol do interesse coletivo (BUCCl, 2006).

De semelhante modo, Derani (2002, p. 239) leciona que as políticas são chamadas de pública quando essas"ações são comandadas pelos agentes estatais e destinadas a alterar as relações sociais existentes. Logo, pode-se dizer que as políticas públicas se concretizam por meio de prestações positivas do Estado.

Bucci (2006, p. 39), por seu turno, explicita que as políticas públicas são programas de ação governamental que resultam de um processo ou de um conjunto de processos que possui como objetivo coordenar os meios à disposição do Estado e as atividades privadas, "para a realização de objetivos socialmente relevantes e politicamente determinados".

Essa identificação das políticas públicas como um processo fica bem nítida ao se analisar as chamadas fases ou etapas de formulação das políticas, as quais podem ser sucinta e sequencialmente descritas da seguinte maneira: identificação do interesse, agenda, formulação, implementação e avaliação (SECCHI, 2010).

A identificação do interesse, em que pese não ser uma tarefa simples, é o primeiro passo para se transformar uma situação de dificuldade em uma política pública, pois nela será definido e identificado o interesse público. Essa fase, segundo Bucci (2006), é marcada pela discricionariedade do administrador, pois exige a determinação de pressupostos materiais que informem e embasem a decisão por meio da qual será desencadeada a ação administrativa.

Passada a etapa de identificação do interesse, passa-se à formação da agenda, que é definida por Schmidt (2008, p. 2316) "como um elenco dos problemas e assuntos que chamaram a atenção da sociedade e do governo", ou seja, é a fase de inclusão de determinado pleito ou necessidade na lista de prioridades do poder público.

Intitulada de formulação de políticas, é na quarta etapa que ocorre o estabelecimento de objetivos, estratégias e soluções para das dificuldades. Afinal, 
sendo possível alcançar um objetivo por diversos caminhos, é necessário definir qual deles será utilizado (SECCHI, 2010).

Depois de formulada a política pública, inicia-se a sua implementação, "que deverá observar os princípios e diretrizes, prazos, metas quantificadas etc" (MASSAARZABE, 2006, p. 70). Assim, a fase de implementação da política pública deve ser cuidadosamente pensada, pois é o momento no qual o planejamento anteriormente estruturado é convertido em ação.

Na quinta e última fase é quando se realiza a avaliação da política pública implementada, momento no qual são verificados os impactos causados pela mesma, o cumprimento dos seus objetivos, além da existência de algo que possa ser modificado (BUCCl, 2006).

No entanto, em que pese essa separação didática, Massa-Arzabe (2006) adverte que, na prática, esse processo não deve ser visto de forma tão linear, com fases totalmente separadas e que se sucedem, pois como a formulação de uma política pública acontece em ciclos, que estão intimamente interligados, não é possível se delimitar, com precisão, quando se encerra um e inicia outro.

No que tange às políticas ambientais no Brasil, foi somente a partir da década de 1930 que as primeiras ações por parte do poder público começaram a ser desenvolvidas, em que pese a maior parte das normas gerais relativas a temática terem sido instituídas somente na década de 90 (ANTUNES, 2008).

Nessa linha, Granziera (2009, p. 270) salienta que as normas ambientais, as quais podem ser editadas em forma de leis, decretos, resoluções, deliberações, portarias e outras formas de atos administrativos normativos, são "mandamentos que condicionam as atividades públicas e particulares" e que possuem como finalidade impedir que danos ao meio ambiente sejam causados por determinadas atividades. Entretanto, segundo o entendimento da autora, a criação de normas ambientais, por si só, não é capaz de garantir a efetividade e aplicação das mesmas, haja vista que essas requerem uma pluralidade de esforços e de institutos, que podem ser tanto de ordem pública como privada, a fim de dar maior efetividade à proteção ambiental. 
Proteção que, segundo Lanfredi (2002), diante da complexidade e importância da matéria, exige a aplicação de instrumentos, a atuação integrada e solidária do poder público, assim como da coletividade, na política ambiental.

É justamente em razão da necessidade desse engajamento da sociedade com o poder público que o município assume lugar de destaque para 0 desenvolvimento de políticas públicas ambientais, pois é na esfera local que os problemas e as necessidades cotidianas da população são melhores conhecidos e tendem a ser mais rapidamente resolvidos e atendidos.

\section{O PRINCÍPIO DA SUBSIDIARIEDADE E A CIDADANIA NO ESPAÇO LOCAL}

A Constituição Federal de 1988, segundo disposto no artigo 18, caput, do seu texto, adotou o modelo federalista de divisão espacial do poder em entes dotados de autonomia. Tais entidades correspondem à União, Estados, Distrito Federal e Municípios (BRASIL, 1988).

Conforme Meirelles (2010), o reconhecimento do Município como ente federado dotado de autonomia, é uma peculiaridade do Estado brasileiro, haja vista que os demais Estados federados não outorgam aos seus entes locais a capacidade de autogoverno, auto-administração e auto-legislação.

Nesse mesmo sentido, é a lição de Corralo (2006, p. 153), quando aduz que "ao considerar o Município um ente integrante da Federação brasileira, o ordenamento constitucional pátrio elevou o Município a uma condição antes não alcançada na história brasileira e sem similar nas constituições modernas".

Tal condição, segundo o autor, é que facilita a descentralização da prestação do serviço público, ou seja, permite uma maior participação dos cidadãos nos assuntos de seu interesse, garantindo maior eficiência e eficácia na formulação de políticas públicas que visem atender as necessidades locais.

Nessa linha, pode-se dizer, então, que os Municípios, ao lado dos Estados e da União, são detentores de legítimo poder estatal, dentro de seu território. "Sua autonomia é tanto de natureza administrativa como política. Seu peculiar interesse local e a eletividade da administração local são os dois princípios que formam a base sobre a qual se ergue a estrutura municipal brasileira" (KRELL, 2003, p. 42). 
Não obstante, Baracho (1996, p. 51) entende, ainda, que em razão do Município ser a entidade intermediária entre os indivíduos e o Estado, é nele que o princípio da subsidiariedade melhor se concretiza, desde que, obviamente, o indivíduo local não seja visto como um ser abstrato, "[...] mas concreto, onde aparece como cidadão, usuário, vizinho, contribuinte, consorciado e participante direto na condução e fiscalização das atividades do corpo político, administrativo e prestacional".

Nessa linha, Hermany (2012, p. 43) leciona que "a subsidiariedade, como critério definidor de competências no âmbito interno, mostra-se extremamente ponderada e equilibrada, ao mesmo tempo em que evidencia a importância do espaço de poder - muito especialmente do Município".

Até mesmo porque, "a partir da noção de subsidiariedade, não apenas as estruturas institucionais locais são valorizadas, mas também a articulação dos atores sociais tanto nos espaços institucionais quanto na sua relação cotidiana" (HERMANY, 2012. p. 44).

A respeito da questão, Baracho (1996, p. 92) salienta que:

Conceitua-se subsidiariedade como princípio pelo qual as decisões,
legislativas ou administrativas, devem ser tomadas no nível político mais
baixo possível, isto é, por aqueles que estão o mais próximo possível das
decisões que são definidas, efetuadas e executadas. Está assim o princípio
de subsidiariedade relacionado com a situação constitucional definida nas
competências dos entes que compõem o tipo de Estado consagrado
(unitário, autonômico, regional e federal) e o processo de descentralização
política e administrativa.

Assim sendo, observa-se que a subsidiariedade atribui condições para que o cidadão participe, sinta-se parte integrante das decisões tomadas no seu Município, ou nas palavras de Hermany (2012, p. 21), "a subsidiariedade confere elementos para a soberania do indivíduo, pois aproxima o diálogo do cidadão, estimula a participação política, traz a abertura de diálogo pluralista e com as minorias".

Ainda, segundo Hermany (2012, p. 42), "o princípio da subsidiariedade remete-nos a uma perspectiva de valorização dos espaços mais próximos do cidadão, de forma que fortalece as estratégias de decisão formuladas a partir da esfera local de poder".

Conforme leciona Baracho (1996, p. 30-31):

O princípio de subsidiariedade, invocado por numerosos textos pontifícios resume-se em uma ideia simples: as sociedades são subsidiárias em 
relação à pessoa, ao passo que a esfera pública é subsidiária em relação à esfera privada. Como corolário, não se deve transferir a uma sociedade maior aquilo que pode ser realizado por uma sociedade menor. Tratando-se de coletividade intermediária, toma-se mais adequado determinar a natureza da autonomia, que deve ser consentida.

Logo, é possível afirmar que o princípio da subsidiariedade pode ser visto como um instrumento "utilizável pelos governantes, na procura de equilíbrios, necessários a redefinir as novas mudanças procuradas pela sociedade, na compreensão e efetivação de suas necessidades" (BARACHO, 1996, p. 57), especialmente na esfera local.

Isso ocorre, na visão de Hermany (2012, p. 24), por que:

A inserção da participação popular no processo de formação das decisões públicas pode servir como elemento fundamental de diminuição dos efeitos da crise estatal, notadamente no que tange ao financiamento, bem como servir para a legitimação de um espaço estatal (re)qualificado na estrutura contemporânea de decisões globais.

Desse modo, pode-se dizer que a subsidiariedade assume um papel crucial tanto para os Municípios quanto para os cidadãos no que se refere à busca pela cidadania ativa no espaço local, haja vista que essa é pressuposto básico da subsidiariedade (BARACHO, 1996).

Todavia, para que uma participação ativa dos cidadãos seja possível, é necessário que o sujeito se sinta empoderado, pois "a cidadania não é exercida sem que haja um fenômeno emancipatório que prepare o sujeito para as regras do convívio em sociedade [...] e nada mais concretizador e próximo desta cidadania do que o poder local". (HERMANY; BENKENSTEIN; SODER, 2010, p. 241). Assim, pode-se dizer que os conceitos de cidadania, espaço local e empoderamento convergem.

Daí, novamente, se observa a importância do princípio da subsidiariedade, pois ele "[...] estimula que a persecução do interesse público seja engajada pelo indivíduo ou por corpos sociais intermediários entre o cidadão e o Estado" (HERMANY, 2012, p. 26), ou seja, ele insita que as decisões, sempre que possível, sejam tomadas e compartilhadas na esfera mais próxima possível dos cidadãos a que se destina.

No entanto, para que haja essa união de esforços, a participação dos cidadãos deve ser estimulada, pois é indiscutível a estreita relação que há entre cidadania e participação, haja vista que:

R. Inter. Interdisc. INTERthesis, Florianópolis, v.14, n.3, p.104-121 Set.-Dez. 2017 
[...] a cidadania necessita da participação social para assegurar sua concretização, dinamismo, crescimento e maturação [...] a participação social pressupõe, para sua concretização e exercício, a cidadania entendida como conquista e reconhecimentos de direitos. Participar significa fazer parte e tomar parte, significa influir ativamente na escola e na construção dos destinos sociais e na solução dos problemas vivos pela comunidade (CASTRO; BAETA, 2008, p. 134).

Assim sendo, verifica-se que o princípio da subsidiariedade exige a descentralização do exercício do poder para as esferas mais próximas dos cidadãos, pois sem descentralização não há autonomia e, sem autonomia, não há como assegurar que no espaço local, por meio de políticas públicas, a cidadania seja fortalecida.

\section{O FORTALECIMENTO DA CIDADANIA NO ESPAÇO LOCAL COMO INSTRUMENTO DE EFETIVAÇÃO DE POLÍTICAS PÚBLICAS DE PROTEÇÃO AMBIENTAL}

O termo cidadania, da forma como é hoje concebido, possui sua origem no latim e se refere, etimologicamente, a todo o ser humano que faz parte de uma cidade civitas. Assim, em uma primeira análise, poderia se dizer "cidadão é aquele que habita a cidade". (GORCZEVSKI; MARTIN, 2011, p. 25). Todavia, já na Grécia, esse termo era dotado de um maior significado.

Faz-se, aqui, essa referência, porque apesar do termo atualmente utilizado ter sua origem no latim, a noção de cidadania surgiu na Grécia, designando a condição das pessoas que faziam parte da administração judicial e deliberativa das cidades, especialmente homens adultos e filhos de cidadãos. Portanto, observa-se que nem todos os seres humanos detinham a condição cidadão, mas, apenas, um determinado grupo (LOUREIRO, 2011).

O mesmo ocorria em Roma, onde os plebeus e os escravos não eram considerados cidadãos, pois a ideia de cidadania estava vincula ao direito de participação e pertencimento, "[...] um status de homem livre" (GORCZEVSKI; MARTIN, 2011, p. 40).

Por essa razão, Warat (2001) afirma que a cidadania sempre constituiu uma classe VIP, pois sendo o cidadão aquele que possui voz, poder de opinar e decidir, tais prerrogativas excluíam a maior parte da população. 
Não obstante isso, de acordo com Gorczevski e Martin (2011), foi a partir das concepções ateniense e romana de cidadania que os pilares históricos do seu conceito se formam, quais sejam: o direito de pertencer a uma comunidade e o direito de participação política.

Nessa linha, Pinsky e Pinsky (2013) entendem a cidadania como a participação do ser humano em uma comunidade política, na qual ele pode gozar de direitos civis e participar do processo de decisão dos destinos da sociedade onde vive.

De modo semelhante, Loureiro (2011, p. 175) afirma que "[...] cidadania é o direito a ter direitos, além do dever de lutar por estes. Não é só isso, porém, cidadania também representa a necessidade de reconhecimento de novos direitos".

No entendimento de Martin (2005), a cidadania compõe-se de três elementos principais, quais sejam: 1) a garantia de determinados direitos, assim como a obrigação de cumprir certos deveres na sociedade em que se vive; 2) pertencer a uma comunidade política; e, derradeiramente, 3) a oportunidade de contribuir na vida política da comunidade mediante a participação ativa.

Vieira (2001, p. 35), por seu turno, assevera que “[...] a cidadania é constituída tanto por direitos passivos de existência, legalmente limitados, como por direitos ativos que propiciam a capacidade presente e futura de influenciar o poder político".

Em razão disso, Gorczevski e Martin (2011) destacam que o conceito de cidadania não pode ser visto como algo estanque, já que ele se encontra em constante evolução e transformação, assumindo as mais distintas formas nos diferentes tempos e contextos sociais.

Todavia, apesar disso, entende-se que, independentemente da época ou sociedade, a participação dos cidadãos na esfera pública encontra-se intimamente vinculada ao conceito de cidadania, pois ser cidadão é mais do que ter assegurado direitos civis e políticos, é contribuir, respeitar e fazer parte das decisões da sociedade.

Essa consciência a respeito da importância da participação e consequente exercício da cidadania são de extrema relevância, pois, à medida que a sociedade "[...] se considera responsável pelo processo de formação das decisões públicas, 
deixa de adotar uma postura clientelista, passando a contribuir com o poder público na definição, realização e posterior controle das políticas públicas" (HERMANY, 2012, p. 85).

A respeito da questão, Baracho (1996) entende que é nos municípios que as políticas públicas são, de fato, concretizadas, o que acaba por consolidar, também, a estrutura federativa, pois no espaço local a solução dos problemas da população consegue ser melhor e mais rapidamente alcançada do que no âmbito nacional.

Nesse sentido, Baracho (1996, p. 19-20) salienta:

O melhor clima das relações entre cidadãos e autoridades deve iniciar-se
nos municípios, tendo em vista o conhecimento recíproco, facilitando o
diagnóstico dos problemas sociais e a participação motivada e responsável
dos grupos sociais na solução dos problemas, gerando confiança e
credibilidade. As políticas públicas, através da estrutura e de operação do
governo local, tomam nova conscientização, com referencia ao conceito
político de federalismo.

De modo semelhante é o posicionamento de Hermany (2007, p. 263), quando destaca que são os governos locais os responsáveis pela implementação de políticas públicas:

São justamente os governos locais os responsáveis pela execução de políticas públicas adequadas para o fortalecimento da qualidade de vida, seja em função da (re)definição de competências constitucionais, seja em virtude da crise de financiamento do Estado Nacional, que o incapacita de atender com efetividade às demandas da população. Tais razões justificam a importância, até paradoxal, do poder local para o desenvolvimento econômico na sociedade globalizada, vinculado ao conceito de qualidade de vida como fator de produtividade e, por conseguinte, de eficiência do sistema produtivo.

Assim, pode-se dizer que, com base na subsidiariedade, a implementação de políticas públicas voltadas ao espaço local pode ser vista como um instrumento de fortalecimento da cidadania e melhoria da qualidade de vida da população.

Nessa linha, também é o entendimento de Baracho (1996, p. 76) quando sustenta que o princípio da subsidiariedade "é instrumento da cidadania plena e participante, criador de formas de atuação social". Isso porque, o referido princípio, "[...] faz apelo à sociedade civil para acompanhar as tarefas de interesse geral, pelo que dá resposta a muitas questões contemporâneas".

Hermany (2012, p. 98), por seu turno, assevera que "é certo que a participação nas decisões administrativas locais amplia sensivelmente o nível de cidadania, potencializando os espaços de abertura institucional, evitando, com isso, a burocratização da Administração Pública". 
Daí a importância de se expandir, nos Municípios, os mecanismos que estimulem e possibilitem que o cidadão, no cotidiano, participe das decisões políticas, pois esse "[...] exercício constante e permanente contribui de forma definitiva para uma nova construção da cidadania" (HERMANY, 2012, p. 125), circunstância que auxilia na efetivação e concretização das políticas públicas no espaço local.

Em razão disso, verifica-se que o fortalecimento da cidadania no espaço local pode ser um instrumento de concretização de políticas públicas, em especial aquelas que tratam da proteção ambiental, haja vista que somente é possível assegurar um meio ambiente sadio e ecologicamente equilibrado se a sociedade e o poder público unirem esforços e atuarem conjuntamente na consecução desse fim.

Até mesmo porque, quando se trata da tutela ambiental, nem o poder público e, tão pouco, a sociedade, sozinhos, conseguirão efetivar esse direito fundamental por intermédio de políticas públicas, pois essas requerem o engajamento e a atuação integrada de todos os atores, ou seja, uma gestão compartilhada entre o poder público e a sociedade (DIAS, 2003).

Portanto, pode-se dizer que é impossível pensar em políticas públicas de proteção ambiental sem a participação e conscientização social, pois meio ambiente é fonte de recurso essencial à manutenção da vida, de modo que tanto o poder público quanto o cidadão precisam tomar para si o compromisso com a sua preservação, pois, caso contrário, nenhuma medida pública conseguirá atingir sua eficácia plena.

A esse respeito, Sarlet e Fensterseifer (2014, p. 41) lecionam:

Com efeito, a devida aplicação da subsidiariedade fortalece as autonomias dos entes políticos regionais e locais, descentralizando a atuação política e o poder estatal. [...] De tal sorte, o princípio opera justamente no sentido de que o ente político descentralizador (por exemplo, a União) só deve agir quando os entes menores ou inferiores (por exemplo, Estados e Municípios) não tiverem condições estruturais (normativas e fáticas) para resolver determinado problema ambiental, dando forma a um sistema político mais democrático, uma vez que as decisões estariam sendo tomadas por instâncias políticas mais próximas dos cidadãos e, consequentemente, de forma mais direta e participativa.

Isso ocorre, porque a consecução do princípio da subsidiariedade possibilita, por parte dos cidadãos, a obtenção do sentimento de pertencimento, viabilizando, desta forma, a concretização de mudanças nas questões interesse público, dentre 
as quais a tutela do meio ambiente encontra-se diretamente inserida (GIACOBBO e LIPPSTEIN, 2015).

Dessa forma, observa-se que o princípio da subsidiariedade pode ser entendido como um mecanismo que visa garantir a cidadania no espaço local e concretizar as políticas públicas que tenham como finalidade a proteção ambiental, haja vista que esse princípio reconhece que um ente menor, mais próximo do cidadão e conhecedor da realidade, é capaz de proporcionar um maior engajamento social, bem como, na maioria das vezes, resolver as demandas ambientais com mais eficiência.

\section{CONCLUSÃO}

O meio ambiente ecologicamente equilibrado foi elevado à categoria de direito fundamental pela Constituição de 1988, em razão da sua importância para manutenção e preservação da vida tanto das presentes quanto das futuras gerações.

Nesse contexto, vislumbrou-se que a Constituição Federal, ao mesmo tempo em que assegura direitos relativos ao meio ambiente, imputa deveres ao Poder Público e à sociedade no que diz respeito à eficácia desses direitos.

Além disso, observou-se que, apesar de todos os entes federados possuírem competência no que tange à aplicação da legislação ambiental e ao desenvolvimento de políticas públicas, os Municípios são os principais responsáveis, em âmbito local, pela efetivação de tais incumbências constitucionais.

Ademais disso, verificou-se a aplicação do princípio da subsidiariedade na esfera local confere elementos para a soberania do cidadão, pois torna mais próximo os espaços de diálogo com o poder público, o que contribui para o processo de formação das decisões públicas.

Assim, o princípio da subsidiariedade pode ser visto como um mecanismo que confere maior legitimidade aos municípios e que promove a cidadania, pela via da participação democrática da sociedade nas decisões que afetam o seu cotidiano.

Nesse diapasão, percebeu-se uma estrita vinculação entre os conceitos de cidadania, espaço local e subsidiariedade, na medida em que se faz necessária a inter-relação de todos para que a autonomia local seja, de fato, concretizada. 
Constatou-se, também, que, com base na subsidiariedade, a implementação de políticas públicas voltadas ao espaço local pode ser vista como um instrumento de fortalecimento da cidadania e melhoria da qualidade de vida da população.

No que diz respeito às políticas ambientais, averiguou-se que essas exigem, para sua concretização, a aplicação de instrumentos e a atuação integrada e solidária do poder público com a sociedade. Por isso, o município assume lugar de destaque para o seu desenvolvimento, pois a esfera local facilita esse engajamento, haja vista que os processos decisórios se encontram mais próximos da população atingida pela política.

Por fim, constatou-se que a aplicação do princípio da subsidiariedade pode ensejar o fortalecimento da cidadania no espaço local e o desenvolvimento de políticas públicas que tratem da temática ambiental. Contudo, para que isso ocorra, urge a necessidade de se ampliar, nos municípios, os espaços que estimulem e promovam a participação da sociedade nas decisões que the atingem direta ou indiretamente. 


\title{
THE PRINCIPLE OF SUBSIDIARITY AND THE STRENGTHENING OF CITIZENSHIP IN LOCAL SPACE AS AN INSTRUMENT FOR THE EFFECTIVENESS OF PUBLIC POLICIES FOR ENVIRONMENTAL PROTECTION
}

\begin{abstract}
:
Care for the environment plays a fundamental role in preserving the quality of life, as the environmental problems resulting from urban sprawl, as well as high levels of consumption and disposal, are sources of global concern and challenge society and public power. In view of this reality, the present article aims to verify whether the strengthening of citizenship in local space, based on the principle of subsidiarity, can be configured as an instrument for the implementation of public policies for environmental protection. For this, a qualitative approach to the theme was chosen. It was concluded that the application of the principle of subsidiarity can lead to the strengthening of citizenship in the local area and the development of public policies that deal about environmental issues, inasmuch as they are expanded, in the municipalities, the spaces of participation of the society in political decisions.

Keywords: Citizenship. Subsidiarity. Local Power. Public Policies. Environmental Protection.

\section{EL PRINCIPIO DE LA SUBSIDIARIEDAD Y EL FORTALECIMIENTO DE LA CIUDADANÍA EN EL ESPACIO LOCAL COMO INSTRUMENTO DE EFECTIVIDAD DE POLÍTICAS PÚBLICAS DE PROTECCIÓN AMBIENTAL}

\section{Resumen:}

El cuidado con el medio ambiente tiene un papel fundamental en la preservación de la calidad de vida, pues los problemas ambientales derivados de la expansión urbana, así como de los altos niveles de consumo y descarte, son fuentes de inquietud global y desafían a la sociedad y al poder público. Ante esta realidad, el presente artículo tiene por objeto verificar si el fortalecimiento de la ciudadanía en el espacio local, con base en el principio de subsidiariedad, puede configurarse como un instrumento de efectividad de políticas públicas de protección ambiental. Para ello, se optó por un enfoque cualitativo del tema. Se concluyó, por consiguiente, que la aplicación del principio de subsidiariedad puede dar lugar al fortalecimiento de la ciudadanía en el espacio local y el desarrollo de políticas públicas que traten de la temática ambiental, siempre que se amplíen, en los municipios, los espacios de participación de la sociedad en las decisiones políticas.

Palabras clave: Ciudadanía. Subsidiariedad. Poder Local. Políticas Públicas. Protección Ambiental. 


\section{REFERÊNCIAS}

ANTUNES, Paulo de Bessa. Direito Ambiental. 11. ed. Rio de Janeiro: Lumen Juris, 2008.

BARACHO, José Alfredo de Oliveira. O princípio de subsidiariedade: conceito e evolução. Rio de Janeiro: Forense, 1996.

BRASIL. Constituição (1988). Constituição da República Federativa do Brasil.

Disponível em: <

http://www.planalto.gov.br/ccivil 03/constituicao/constitui\%C3\%A7ao.htm >. Acesso

em: 21 nov. 2016.

- Ministério do Meio Ambiente. Declaração da Conferência de ONU no

Ambiente Humano. Estocolmo, 5-16 de junho de 1972. Disponível em: <http://www.mma.gov.br/estruturas/agenda21/arquivos/estocolmo.doc> Acesso em: 21 nov. 2016.

BUCCI, Maria Paula Dallari. Direito Administrativo e Políticas públicas. São Paulo: Saraiva, 2006.

CASTRO, Ronaldo Sousa de; BAETA, Anna Maria. Autonomia intelectual: condição necessária para o exercício da cidadania. In: LOUREIRO, Carlos Frederico Bernardo; LAYRARGUES, Philippe Pomier; CASTRO, Ronaldo Sousa de (orgs.).

Educação ambiental: repensando o espaço da cidadania. 4. ed. São Paulo: Cortez, 2008.

CORRALO, Giovani da Silva. Município: Autonomia na Federação Brasileira. Curitiba: Juruá, 2006.

DERANI, Cristiane. Privatização e serviços públicos: as ações do Estado na produção econômica. São Paulo: Max Limonad, 2002.

DIAS, Jean Carlos. Políticas públicas e questão ambiental. Revista de Direito Ambiental. São Paulo, v. 31, n. 8, p. 117-135, jul./set., 2003.

GIACOBBO, Guilherme Estima; LIPPSTEIN, Daniela. O município como ente privilegiado de construção e controle das decisões públicas. In: LIPPSTEIN, Daniela; 
GIACOBBO, Guilherme Estima; MOREIRA, Rafael Bueno da Rosa. (Org.) Políticas Públicas, Espaço Local e Marxismo. Santa Cruz do Sul: Esserenel mondo, 2015.

GORCZEVSKI, Clovis; MARTIN, N. B. A necessária revisão do conceito de cidadania: movimentos sociais e novos protagonistas na esfera pública democrática. Santa Cruz do Sul: EDUNISC, 2011.

GRANZIERA, Maria Luiza Machado. Direito Ambiental. São Paulo: Atlas, 2009.

HERMANY, Ricardo. Município na Constituição. O poder local na constitucionalismo Luso-Brasileiro. Curitiba: Juruá, 2012.

; BENKENSTEIN, Jeanine Cristiane; SODER, Rodrigo Magnos. O empoderamento social e o poder local como instrumentalizadores na formulação democrática de políticas públicas municipais. In: SCORTEGAGNA, Fernando; COSTA, Marli da; HERMANY, Ricardo. Espaço local, cidadania e políticas públicas. Santa Cruz do Sul: Editora IPR, 2010.

. (Re) discutindo o espaço local: uma abordagem a partir do direito social de Gurvitch. Santa Cruz do Sul: EDUNISC: IPR, 2007.

KRELL, Joachim Andreas. O Município no Brasil e na Alemanha: Direito e Administração Pública comparados. São Paulo: Oficina Municipal, 2003.

LANFREDI, Geraldo Ferreira. Política Ambiental: busca de efetividade de seus instrumentos. São Paulo: Revista dos Tribunais, 2002.

LOUREIRO, Patrícia. A cidadania da União Europeia: mito ou realidade? In: SOUSA, M. T. C.; LOUREIRO, P. (Org.). Cidadania: novos temas, velhos desafios. Ijuí: Unijuí, 2009.

MARTIN, Nuria Belloso. Os novos desafios da cidadania. Santa Cruz do Sul: EDUNISC, 2005. Tradução de: Clovis Gorczevski.

MASSA-ARZABE, Patrícia Helena. Dimensão jurídica das políticas públicas. In: BUCCI, Maria Paula Dallari (Org.). Políticas Públicas: reflexões sobre o conceito jurídico. São Paulo: Saraiva, 2006. 
MEIRELLES, Hely Lopes. Direito Administrativo Brasileiro. Malheiros, São Paulo, 2010.

PINSKY, Jaime; PINSKY, Carla Bessanezi. História da Cidadania. 6. Ed. São Paulo: Contexto, 2013.

SARLET, Ingo Wolfgang. A eficácia dos direitos fundamentais: uma teoria geral dos direitos fundamentais na perspectiva constitucional. 10. ed. Porto Alegre: Livraria do Advogado, 2009.

; FENSTERSEIFER, Tiago. Princípios do direito ambiental. São Paulo: Saraiva, 2014.

SCHMIDT, João Pedro. Para entender as políticas públicas: aspectos conceituais e metodológicos. In: REIS, J.R; LEAL, R.G. (org.) Direitos sociais e políticas públicas: desafios contemporâneos. Tomo 8. Santa Cruz do Sul: Edunisc, 2008.

SECCHI, Leonardo. Políticas públicas: conceitos, categorias de análise, casos práticos. São Paulo: Atlas, 2010.

SOUZA JÚNIOR, Cezar Saldanha. O Tribunal Constitucional como Poder. São Paulo: Memória Jurídica, 2002.

VIEIRA, Liszt. Os argonautas da cidadania: sociedade civil na globalização. Rio de Janeiro: Record, 2001.

WARAT, Luis Alberto. Ciudadania y derechos humanos de la otredad. In: MARTIN, Núria Belloso. Los nuevos desafios de la ciudadanía. Burgos: Servicio de Publicaciones de laUniversidad de Burgos, 2001.

\section{Artigo:}

Recebido em 14de Março de 2017

Aceito em 25 de Julho de 2017. 